\title{
Three-stage quantitative approach of understanding household adaptation decisions in rural Cambodia
}

\author{
Xi Jiao
}

Department of Food and Resource Economics, University of Copenhagen, Frederiksberg C, Denmark and School of Economics, Yunnan University, Kunming, China

Yuan Zheng

Department of Strategy and Partnerships, The New Development Bank, Shanghai, China, and

Zhen Liu

School of Business, Nanjing Normal University, Nanjing, China

\begin{abstract}
Purpose - A better understanding of the processes that shape households' adaptation decisions is essential for developing pertinent policies locally, thereby enabling better adaptation across scales and multiple stakeholders. This paper aims to examine the determinants of household decisions to adapt, it is also possible to target factors that facilitate or constrain adaptation. This helps to identify key components of current adaptive capacity, which leads to important insights into households' competence to adapt in the future.

Design/methodology/approach - This paper takes a full-pledged approach examining factors and processes that shape households' climate adaptation decision-making in rural Cambodia at three levels: adaptation status, adaptation intensity and choices of adaptation strategy. The three-stage analyses are materialized by applying the double hurdle model and multivariate probit model, which provides a potential way to systematically assess household adaptation decision-making in rural settings.

Findings - Results show a high level of involvement in adaptation among local households who are facing multiple stressors including climatic risks. The findings suggest that perceived climate change influence

(C) Xi Jiao, Yuan Zheng and Zhen Liu. Published by Emerald Publishing Limited. This article is published under the Creative Commons Attribution (CC BY 4.0) licence. Anyone may reproduce, distribute, translate and create derivative works of this article (for both commercial and noncommercial purposes), subject to full attribution to the original publication and authors. The full terms of this licence may be seen at http://creativecommons.org/licences/by/4.0/legalcode

Financial support under the Erasmus Mundus Joint Doctorate (EMJD) Programme, Forest and Nature for Society (FONASO), the Research Council of the Danish Ministry of Foreign Affairs National Natural Science Foundation of China: (71603126) and International Cooperation (71911530164) are gratefully acknowledged. The authors would like to express their gratitude for the assistance provided by the Royal University of Agriculture (RUA) in Cambodia and Mr. Poun Sokheoun during the fieldwork, and the support of the Cambodia Development Resource Institute (CDRI), and the Greater Mekong Sub-region Environment Operations Center (GMS EOC) who assisted in producing the map. Above all, the authors would like to thank the villagers and commune officials in the study sites, who generously shared their time and knowledge. We would also like to thank Carsten Smith-Hall, Hasan Moinuddin and Edmond Dounias for their insightful comments and suggestions on earlier drafts.
\end{abstract}

Received 24 January 2019 Revised 6 May 2019 22 July 2019

Accepted 25 October 2019 
IJCCSM 12,1

households' decisions in both adaptation status and intensity. Access to financial credit, farmland size, water availability and physical asset holdings are identified as key factors promoting the adoption of more adaptation measures. To facilitate adaptation, collective effort and support at community level is important in providing knowledge based climate information dissemination and early warning systems. Public sector support and development aid programs should focus on positive triggers for targeted community and household adaptation.

Originality/value - The study, to the authors' best knowledge, is one of the first studies to investigate the determinants of local adaptation decision-making systematically in Cambodia. It also provides a comprehensive approach to improve understanding of adaptation decision-making processes by exploring how various capital assets are associated with different stages of adaptation decisions. The findings contribute to policy implications enlightening adaptation planning at multi-scales with knowledge of key factors, which enhance local adaptive capacity to reduce climate change vulnerability.

Keywords Adaptive capacity, Southeast Asia, Climate change, Rural livelihoods, Adaptation decision

Paper type Research paper

\section{Introduction}

It is generally acknowledged that the poor in developing countries are vulnerable to shocks and crisis with limited adaptive capacity; and climate change induced adverse impact is one of the many stressors they may face, due to higher dependence on climate-sensitive income sources (e.g. agricultural and natural resource-based) (Mertz et al., 2009; Piya, 2019). The importance of using bottom-up approaches to examine socio-economic aspects of climate change at the local level has been highlighted by recent research to acknowledge context-specific vulnerability and capacity to adapt in a dynamic social-ecological system confronted with multiple drivers of change (Piya, 2019). Adaptation, defined as the adjustment in the system to a new or changing environment (i.e. climatic stimuli in the context of climate change) (Evers and Pathirana, 2018; Smit et al., 2000; Smit and Wandel, 2006), not only can be planned and initiated by the government but also requires autonomous adjustments at the household and community level (Smit et al., 2000).

Adaptive capacity is defined as the ability of a system to moderate the potentially adverse impacts of climate change and take advantage of arising opportunities (IPCC, 2007). Several conceptual frameworks have characterized its elements as related to a composite of socio-economic, technological, informational, institutional and psychological factors (Grothmann and Patt, 2005; Yohe and Tol, 2002). In the context of rural livelihoods, these factors are interpreted in a sustainable livelihood approach as portfolios of capital assets (i.e. natural, human, financial, social and physical) that households can build up to tackle risks, including climate risks (Li et al., 2016; Piya, 2019; Scoones, 1998). Thus, adaptation to climate change and variability is regarded as an intrinsic part of households' overall risk management strategies in rural reality. A better understanding of the processes that shape households' adaptation decisions is essential for developing pertinent policies locally, thereby enabling better adaptation across scales and multiple stakeholders. By examining the determinants of household decisions to adapt, it is also possible to target factors that facilitate or constrain adaptation. This helps to identify key components of current adaptive capacity, which leads to important insights into households' competence to adapt in the future (Füssel and Klein, 2006).

Studies on socio-economic aspects of climate change has gained momentum in the past decade. There is limited empirical evidence concerning the determinants of households' adaptation decisions (Below et al., 2012; Vincent, 2007). A few studies have examined what drives discrete choices of adaptation by investigating the factors that affect the option of 
whether to adapt (Deressa et al., 2011; Maddison, 2007) or various but mutually exclusive adaptation choices (Bryan et al., 2013; Deressa et al., 2009; Gbetibouo et al., 2010; Molua, 2009; Waibel et al., 2018) or the probability of one household carrying out multiple adaptation measures (Piya et al., 2013). Other studies have addressed what influences the depth of adaptation, i.e. how many adaptation practices were implemented by individual households (Below et al., 2012; Esham and Garforth, 2012; Gong et al., 2018). The majority of these studies focus on rural communities in Africa (Bryan et al., 2013; Deressa et al., 2009; Gbetibouo et al., 2010), with a few in Asia (Gong et al., 2018; Piya et al., 2013; Wang et al., 2010) and rarely in Southeast Asia (Waibel et al., 2018).

In this study, we incorporated the above considerations and research gaps from previous studies and investigated three dimensions of household adaptation decisions in the case study of Cambodia, following Noltze et al. (2012) (Figure 1). These are:

(1) adaptation status, referred to as whether any adaptation has been undertaken by the household or not; if yes;

(2) adaptation intensity, defined as the extent (how many adaptation measures) to which adaptation has been performed; and

(3) adaptation strategy, referred to categories of specific adaptation measures undertaken by households that are classified into different themes of adaptation actions.

The geographic focus of the study is Cambodia. As one of the recipients of financial support from the least developed countries fund, Cambodia has begun to launch adaptation actions nation-wide (D'Agostino and Sovacool, 2011). The existing literature reports mostly on experiences from specific adaptation projects in Cambodia (D'Agostino and Sovacool, 2011; Ly et al., 2012; Sovacool et al., 2012), while little has been done to examine adaptation decisions and practices from local actors' perspective (Resurreccion et al., 2008). This paper aims to conduct a systematic analysis on what factors influence households' adaptation decisions in rural Cambodia at three dimensions:

(1) adaptation status;

(2) adaptation intensity; and

(3) adaptation strategy (category).

The study, to our knowledge, is one of the first studies to investigate the determinants of local adaptation decision-making in Cambodia. It also provides a comprehensive approach to improve understanding of adaptation decision-making processes by exploring how
Household adaptation decisions

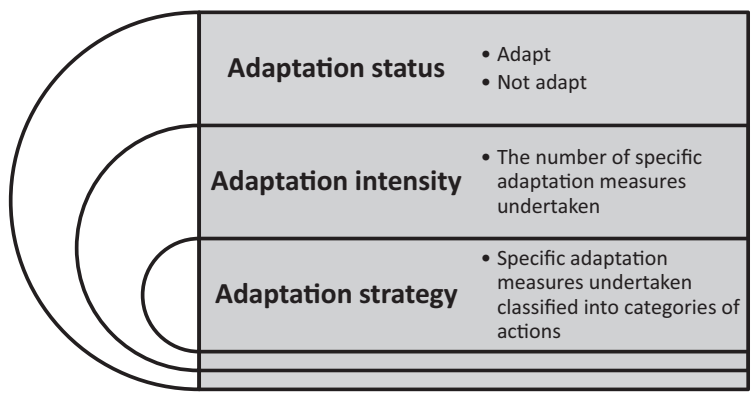

Figure 1. Conceptual framework of household adaptation decisions in the study 
IJCCSM 12,1

various capital assets are associated with different stages of adaptation decisions. The findings contribute to policy implications by enlightening adaptation planning at multiscales with knowledge of key factors, which enhance local adaptive capacity to reduce climate change vulnerability.

\section{Material and methods}

\subsection{Study sites}

Cambodia is anticipated to be severely affected by climate change, as agriculture is a major pillar of its economy. A decrease of $10-20$ per cent in rice yields for the 2020s is projected without adaptation under climate change scenarios (Kim et al., 2018). In this study, fieldwork was undertaken in 15 villages in three communes in Cambodia: Takaen in Kampot Province, Sangkae Satob in Kampong Speu Province and Tum Ring in Kampong Thom Province (Figure 1), which were initially selected in 2008 for the studies of the Poverty Environment Network (PEN, 2007). The studied communes cover a total land area of 70,082 hectares with a population of 23,460 (NCDD, 2010). The majority is Khmer; other ethnic minority groups include Souy and Khmer Muslim. Site selection criteria included:

- large areas, which have been deforested within the last 10-15 years (agricultural frontier); and

- the presence of some degree of reliance on environmental products at the household level.

The sites are all located in the lowlands, including the transition area between lowlands and mountains, and reflect the variations in rainfall patterns and other climatic characteristics.

More specifically, Takaen Commune is located in the coastal cardamom area. Annual rainfall is relatively high, ranging from 2,600 to 3,200 mm. Sangkae Satob Commune is located in the transition zone between the northern Cardamom mountain range and the lowlands of Tonle Sap Lake. The dry season is shorter than four months with low annual rainfall ranging between 800 and $1,400 \mathrm{~mm}$. Tum Ring Commune is a lowland area in a remote part of Kampong Thom Province. The area experiences a relatively long and intensive dry season that lasts for more than four months. Annual rainfall ranges from 1,400 to 2,000 $\mathrm{mm}$ with an average of $1,700 \mathrm{~mm}$ (Ra et al., 2011) (Figure 2).

Rural livelihoods in the study areas are a combination of subsistence and cash incomeoriented activities with the transition to a more diversified livelihood portfolio. Agricultural production remains the most important component of local livelihoods. The collection of forest and other environmental products also contributes significantly to household income portfolio (Ra et al., 2011). Seasonal and long-term migration and remittances are becoming important for livelihood strategies. Major climate risks in the study area are droughts and minor floods (Bylander, 2015; Nguyen et al., 2009), which have a direct impact on rice and other crop productivity. In general, there are no irrigation systems at the study sites, and paddy fields located at higher elevations and away from water bodies are at increased risk of drought and dry spells.

\subsection{Data collection}

Participatory group discussions and structured household questionnaire surveys were used as primary data collection methods. Data collection and handling followed the procedures developed by the PEN (Angelsen et al., 2011). A total of 600 households were randomly selected initially in 2008, with 200 households in each study site and 40 households in each of the 15 villages (corresponding to $10-30$ per cent of households in each village). Of the originally 


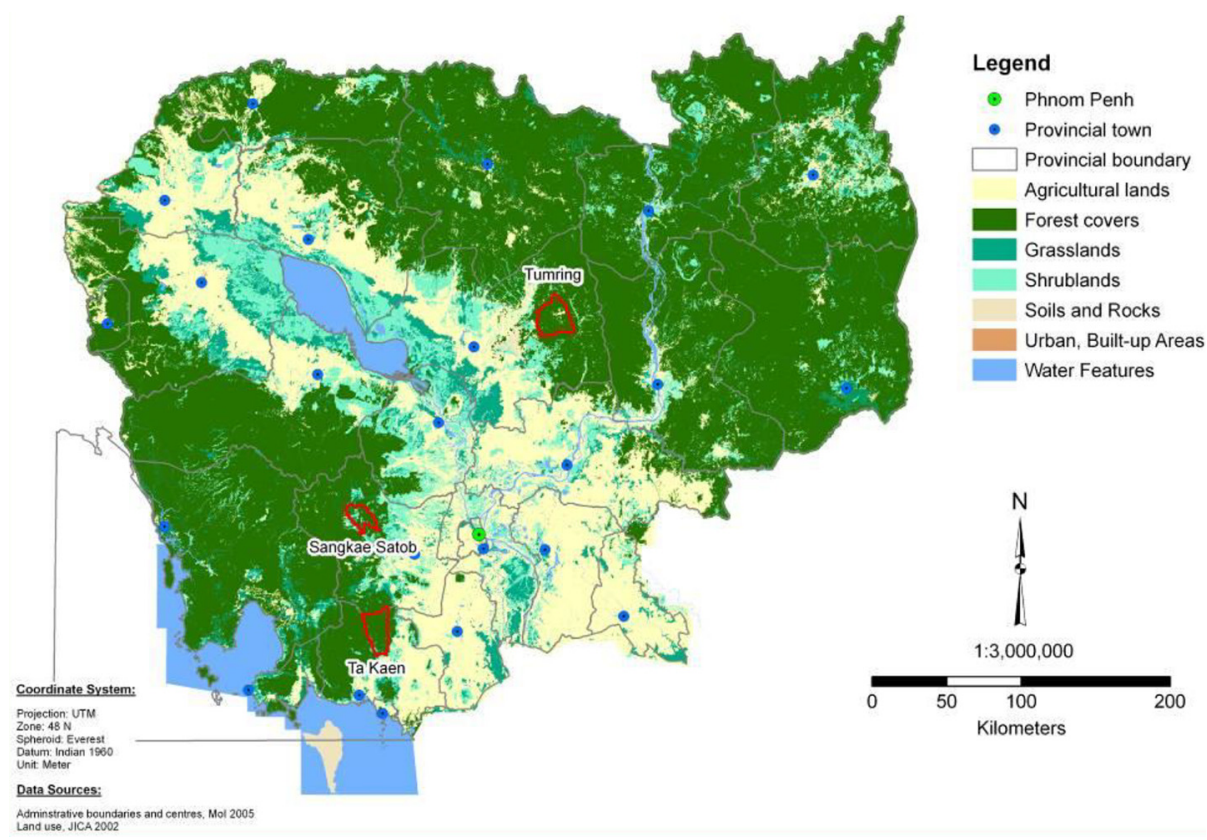

Household adaptation decisions

selected 600 households, 586 households participated in the second wave of the structured household surveys in January of 2013, where the questions for this study on climate change perception and adaptation were incorporated (which was not part of the study in 2008).

The structured questionnaire focussed on households' observations and perception of climate variability and extreme events, past experience of livelihood risks/shocks (especially climate risks and impacts on livelihoods) and adaptation behaviours and decisions, as well as five capital asset holdings and income sources. Experienced local research assistants and enumerators participated in pre-testing of the questionnaire and the survey process. Participatory group discussions were conducted prior to household surveys to gather contextual and qualitative information as inputs to detailed household survey questionnaire design (e.g. to identify localized adaptation measures). Two villages from each study site were selected for group discussions, reflecting diversified climate risks and livelihood strategies. Groups representing different genders and age and a diversity of livelihood strategies discussed the vulnerability and adaptation matrix, seasonal calendar and historical timelines in six of the villages using interactive flip chart tables and drawings facilitated by local research assistants.

\subsection{Empirical models}

Probit models and Heckman sample selection probit models have been used by previous studies to investigate the decision of households to adapt or not (Deressa et al., 2011; Maddison, 2007). However, adaptation is not simply a yes or no decision, and binary models fail to consider the intensity of adaptation or the relationship between different measures (Noltze et al., 2012; Piya et al., 2013). Continuous models or count models were also used to analyse adaptation intensity (Below et al., 2012; Esham and Garforth, 2012). In our study, we are interested in both decision stages: firstly, the decision to adapt or not, and secondly, the 
IJCCSM

12,1

degree of intensity with which households undertake adaptation measures. Thus, this study uses a double hurdle model (Cragg, 1971), more specifically a Poisson count data hurdle model (Mullahy, 1986) to operationalize the two-stages of the decision-making process in the rural communities in Cambodia, and the approach has been applied in the context of agricultural technology adoption (Langyintuo and Mungoma, 2008; Noltze et al., 2012; Tambo and Abdoulaye, 2012).

$$
\begin{aligned}
& y_{i 1}^{*}=x_{i}^{\prime} \alpha+\mu_{i} \\
& y_{i 2}^{*}=z_{i}^{\prime} \beta+\omega_{i}
\end{aligned}
$$

Adopted from Noltze et al. (2012), equation (1) examines the binary decision to undertake any adaptation measures, whereas the number of adaption measures the household has practiced is represented by equation (2). $y_{\mathrm{i} 1}^{*}$ and $\mathrm{y}_{\mathrm{i} 2}^{*}$ are the two latent variables of adaptation status (whether to adapt any) and intensity (how many measures undertaken). $x_{i}^{\prime}$ and $z_{i}^{\prime}$ are vectors of household characteristics and asset capital variables (Table I), which determine the adaptation decisions, and $\alpha$ and $\beta$ are coefficients to be estimated. $\mu_{i}$ and $\omega_{i}$ represent the respective error terms, which are assumed to be independent and distributed as $\mu_{i} \sim \mathrm{N}$ $(0,1)$ and $\omega_{i} \sim \mathrm{N}\left(0, \sigma^{2}\right)$. More specifically, the first decision stage regarding whether to adopt any adaptation measures $(\mathrm{y}>0)$ is estimated by a binomial logistic regression model; while the second decision stage is based on a conditional distribution of the number of adaptation measures adopted, given $y>0$ (Greene, 2008). The two-part likelihood function used in the model estimation is described in details in Jones (1989) and Noltze et al. (2012).

Further, this study uses a multivariate probit model (MVP) to analyse the determinants of individual adaptation strategy among the studied households in rural Cambodia. MVP enables modelling the probability of choosing more than one adaptation strategy option simultaneously, which overcomes the limitation of the multinomial logit model with strict assumption of independence of the irrelevant alternatives (Piya et al., 2013). The same set of explanatory variables were used for the double hurdle model and the MPV model, which allows the investigation of how specific factors affect different decision stages and types of adaptation strategy.

$$
Z_{i j}=X_{i} \beta+\varepsilon_{i}, \quad i=1, \ldots, \quad n
$$

Following Piya et al. (2013) and Tabet (2007), the MVP model is described as equation (3) above. Where $i=1, \ldots, \mathrm{n}$ are the individual household observations, $j=1, \ldots, \mathrm{J}$ are the available distinct binary adaptation responses; $Z_{\mathrm{ij}}=\left(Z_{\mathrm{i} 1}, \ldots, Z_{\mathrm{ij}}\right)^{\prime}$ presents a $J$-variate normal vector of latent variables and $X_{i}$ is a matrix of covariates composed of explanatory variables, which influence a household's decision regarding adaptation choices; $\beta=\left(\beta_{1}^{\prime}, \ldots, \beta_{\mathrm{J}}^{\prime}\right)$ is a matrix of unknown regression coefficients, $\varepsilon_{i}$ is a vector of residual error distributed as multivariate normal distribution with zero means and unitary variance; $\varepsilon_{i} \sim \mathrm{N}\left(0, \sum\right)$ where $\sum$ is the variance-covariance matrix.

$$
Y_{i j}=\left\{\begin{array}{c}
1 \text { if } Z_{i j}>0 ; \\
0 \text { otherwise }
\end{array}\right\} i=1, \ldots, n \text { and } j=1, \ldots, J .
$$

Let $\mathrm{Y}_{\mathrm{ij}}=\left(\mathrm{Y}_{\mathrm{i} 1}, \ldots, \mathrm{Y}_{\mathrm{ij}}\right)$ denote the $\mathrm{J}$-dimensional vector of observed binary responses taking values $\{0,1\}$ on the $i$-th household. The relationship between $Z_{\mathrm{ij}}$ and $\mathrm{Y}_{\mathrm{ij}}$ is described in equation (4). For further information on the model specification (i.e. likelihood function and correlation matrix), see Piya et al. (2013) and Cappellari and Jenkins (2003). 


\begin{tabular}{|c|c|c|c|c|c|c|}
\hline Variable & $\begin{array}{l}\text { Expected } \\
\text { sign }\end{array}$ & Description & Capital assets & Mean & SD & $\begin{array}{l}\text { Household } \\
\text { adaptation }\end{array}$ \\
\hline Age of HH head & + & Age of household head in years & Human capital & 44.90 & 11.99 & \\
\hline $\mathrm{Age}^{2}$ (of HH head) & - & Age (of household head) squared & Human capital & 2159 & 1149 & \\
\hline $\mathrm{HH}$ size & + & Number of household members & Human capital & 5.14 & 1.76 & \\
\hline Female-headed HH & - & $\begin{array}{l}\text { Household is female headed: } 0= \\
\text { male; } 1=\text { female }\end{array}$ & Human capital & 0.18 & 0.39 & 45 \\
\hline $\begin{array}{l}\text { Education of } \mathrm{HH} \\
\text { head }\end{array}$ & + & $\begin{array}{l}\text { Number of years in school completed } \\
\text { by the household head }\end{array}$ & Human capital & 3.43 & 3.17 & \\
\hline $\begin{array}{l}\text { Health status } \\
\text { (sickness) }\end{array}$ & - & $\begin{array}{l}\text { Number of family members who are } \\
\text { in bad health }\end{array}$ & Human capital & 0.33 & 0.98 & \\
\hline $\begin{array}{l}\text { Perception of } \\
\text { climate change }\end{array}$ & + & $\begin{array}{l}\text { Household perceived changes of } \\
\text { extreme climate events (i.e. flood, } \\
\text { drought) }\end{array}$ & Human capital & 0.96 & 0.21 & \\
\hline $\begin{array}{l}\text { Past experience } \\
\text { with drought }\end{array}$ & + & $\begin{array}{l}\text { The average loss of paddy } \\
\text { production during drought year (in } \\
\text { percentage) compared with normal } \\
\text { production year }\end{array}$ & Human capital & 0.24 & 0.28 & \\
\hline Farmland area & \pm & $\begin{array}{l}\text { Area of cultivated farmland } \\
\text { (hectares) }\end{array}$ & Natural capital & 1.14 & 1.34 & \\
\hline Access to water & + & $\begin{array}{l}\text { Amount of water available to } \\
\text { household farmland: } 1=\text { low } \\
\text { availability or too much water; } 2= \\
\text { moderate; } 3=\text { good for agricultural } \\
\text { production }\end{array}$ & Natural capital & 2.09 & 0.80 & \\
\hline Physical assets & + & $\begin{array}{l}\text { The current value of all physical } \\
\text { assets owned by the household (in } \\
\text { million Riel local currency) }\end{array}$ & Physical capital & 4.87 & 7.82 & \\
\hline Access to market & - & $\begin{array}{l}\text { Distance to the nearest main road (in } \\
\text { kilometers) }\end{array}$ & Physical capital & 0.11 & 0.62 & \\
\hline Access to credit & + & $\begin{array}{l}\text { Number of financial sources } \\
\text { household able to access (i.e. formal } \\
\text { banks and government programs/ } \\
\text { village development fund, self- } \\
\text { organized saving groups, informal } \\
\text { credit from relatives or friends) }\end{array}$ & $\begin{array}{l}\text { Financial } \\
\text { capital }\end{array}$ & 2.04 & 0.67 & \\
\hline Trust & + & $\begin{array}{l}\text { General trust among people living in } \\
\text { the village/community: } 1=\text { no; } 2= \\
\text { partly; } 3=\text { yes }\end{array}$ & Social capital & 2.47 & 0.55 & \\
\hline Sangke Satob & \pm & $\begin{array}{l}\text { Household located in Sangke Satob } \\
\text { commune: } 1 \text { = Yes; } 0 \text { = otherwise }\end{array}$ & $\begin{array}{l}\text { Social, natural, } \\
\text { physical capital }\end{array}$ & 0.34 & 0.48 & $\begin{array}{r}\text { Table I. } \\
\text { Explanatory }\end{array}$ \\
\hline Tum Ring & \pm & $\begin{array}{l}\text { Household located in Tum Ring } \\
\text { commune: } 1=\text { Yes; } 0=\text { otherwise }\end{array}$ & $\begin{array}{l}\text { Social, natural, } \\
\text { physical capital }\end{array}$ & 0.32 & 0.47 & $\begin{array}{l}\text { variables selected for } \\
\text { the empirical models }\end{array}$ \\
\hline
\end{tabular}

\subsection{Model variables}

In the first decision stage - adaptation status, we use the dummy variable (Yes/No), which indicates whether households have taken any adaptation measures. Adaptation intensity is calculated using the simple unweighted sum of adaptation measures households have adopted. We assume that each adaptation measure is equally important depending on the location where it is implemented. All the adaptation measures are then categorized into five broader adaptation strategy categories (Figure 3 ) as the dependent variables for the MPV model.

The choice of explanatory variables was based on the literature review and results from participatory group discussions (Table I). Mixed results have been reported in the literature 


\section{IJCCSM \\ 12,1}

46

Figure 3.

Categorization of adaptation measures into five adaptation strategies

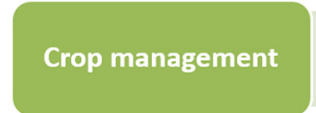

- Introduce new variety (e.g. rice varieties)

- Change to other crops (e.g. cash crops)

- Adjust and manage agricultural calendar

-Improve seedling management

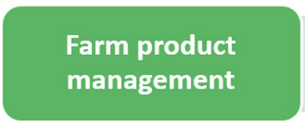

-Value added product processing and management

-Increase in production of paddy rice (i.e. area, seasons)

- Upscale in other agricultural production (i.e. livestock and crops)

- Improve marketing

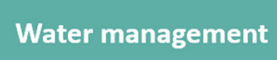

- Flood water drainage

- Water control and management

-Improve water accessibility

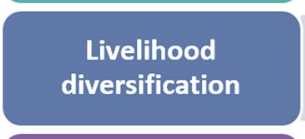

-Aquaculture in the paddy fields

- Shift to other activities

- Stop cultivation

- Migration/remittanc

- Reduce or stop forest-based activities

\section{Farmland}

management

regarding the impacts of age on adaptation, showing both increased and decreased propensity to conduct different adaptation measures (Deressa et al., 2009; Hassan and Nhemachena, 2008; Piya et al., 2013). In this study, we expect that older households are more likely to adapt as they are more experienced in farming. However, we also hypothesize that intention to adapt drops above a certain age threshold given that households have more limited energy and ability to implement adaptation or that they have less need to adapt given reduced consumption. Thus, age-squared is included in the model. The literature also shows varying relations between household size and the uptake of adaptation measures. For instance, larger families were found more likely to carry out soil and water conservation practices (Bryan et al., 2013) and labour intensive measures such as multiple cropping (Hassan and Nhemachena, 2008). In this study, we expect that households with more family members will be more inclined to adapt and conduct strategies that require a larger pool of labour supply such as livelihood diversification. Moreover, the literature has welldocumented gender-specific adaptation measures on account of the differential access of men and women to assets, education, credit and information, which is very much decided by the specific context where adaptation occurs (Below et al., 2012; Bryan et al., 2013; Deressa et al., 2009). In this study, we also expect major variances in adaptation decisions, intensity and types of strategies with regard to gender, and less adaptation practiced by femaleheaded households. Education is another important factor in promoting adaptation and the adoption of agricultural technology (Maddison, 2007; Tambo and Abdoulaye, 2012). We hypothesize a positive impact of education on adaptation as more schooling may enhance households' capabilities to approach, interpret and make use of information pertinent to adaptation. The health conditions of households have seldom been considered when elaborating adaptation decisions in the current literature. In this study, we incorporate this variable (i.e. number of family members who are in bad health) in the analysis and hypothesize that it negatively affects adaptation as it not only reduces the effective labour supply, but also that households may be forced to divert part of their time and money to care for members in need.

Several studies have found that households' perceptions of climate change (changes in long-term temperature, precipitation and climate variability such as drought) and its related impacts are positive and significant determinants of adaptation decision-making 
(Comoé and Siegrist, 2013; Deressa et al., 2011; Deressa et al., 2009; Esham and Garforth, 2012). As drought and flood have been reported as the most frequent and concerned extreme climatic events in the study areas (95.6 per cent of the interviewed households observed irregular flood and drought patterns in recent years), this study focuses on investigating the perception and awareness of the frequency and magnitude of changes regarding these two climatic events. We expect that households, which notice such changes in climate will tend to adapt and with greater intensity with diverse measures to prevent losses or to take advantage of opportunities. We further study the impact of past experience with climate risks on adaptation behaviour measured in terms of crop harvest losses to previous droughts. Theoretical models have underlined past personal experience as an important catalyst of adaptation (Grothmann and Patt, 2005). In this study, we assume that households, which have had bad experiences with climate change events in the past will tend to undertake adaptation using various measures.

The literature has demonstrated mixed effects of farmland area on adaptation, depending on the type of adaptation measures being explored. Households with larger size of farmland were found more likely to change crop varieties, conduct soil and water conservation measures and plant trees (Bryan et al., 2013; Piya et al., 2013; Waibel et al., 2018), while those with less farmland appeared to be supportive of adopting multiple crop or crop-livestock systems with irrigation (Hassan and Nhemachena, 2008). We hypothesize that the farmland area is positively associated with propensity to adapt and adaptation intensity, which increases the probability of uptake of all adaptation strategies except for livelihood diversification. Furthermore, we consider the effect of access to water on adaptation decisions. Bryan et al. (2013) found that access to irrigation enables changing crop type. In this study, we expect that improved access to water stimulates adaptation, in particular strategies managing crops, water and farmland. The literature also suggests that the availability of machinery drives adaptation (Below et al., 2012). In this study, we assume that households, which are richer in physical capital including production machinery (e.g. tractors) and telecommunication devices (e.g. mobile phones), relate positively to various adaptation decision-making processes.

Various studies have noted the significance of access to market in facilitating adaptation of a diverse nature, given the essential role of the market for information gathering and sharing (Below et al., 2012; Hassan and Nhemachena, 2008; Maddison, 2007; Tambo and Abdoulaye, 2012). In this study, access to market is controlled by the distance to the nearest main road. It is expected that households located further away from the main road are less likely to adapt. Similarly, the indispensable role played by access to credit in boosting adaptation in a variety of ways is well documented in the literature (Below et al., 2012; Deressa et al., 2009; Hassan and Nhemachena, 2008; Piya et al., 2013). We hypothesize that households with more sources to accumulate financial capital at their disposal are better able to purchase inputs and invest in costly strategies if needed, and therefore, more likely to adapt with an expanded range of strategies including those in this study. It has been established that different forms of social capital (e.g. social networks, informal institutions) act as key stimulants of adaptation by providing critical conduits to transfer finances and information(Adger, 2003; Wolf et al., 2010), as well as forming common collaborative frameworks. In this paper, we used the level of trust among households as a proxy for social capital, and assume that it is positively associated with different types of adaptation decision-making.

As adaptation is highly context-specific (Smit and Wandel, 2006), we included location dummies to capture the heterogeneity in biophysical and socio-economic conditions across communities, and expect that adaptation decisions vary significantly among households
Household adaptation decisions 
IJCCSM

12,1

48

residing in different geographical zones, as reported in other studies (Deressa et al., 2009; Hassan and Nhemachena, 2008; Piya et al., 2013; Tambo and Abdoulaye, 2012).

\section{Results}

\subsection{Descriptive statistics}

Over 80 per cent of the household survey respondents observed a decrease in total annual rainfall and irregular shifts in rainfall patterns during recent years. Local communities often associate the increased climate risks with loss of forests due to logging, agricultural land conversion and large-scale economic land concessions. The results show that the majority of households have undertaken a variety of adaptation strategies in the study area (Table II). The number of households, which reported no adaptation measures accounted for only five per cent of the sample. On average, households undertook over three adaptation measures ( mean $=3.17, s d .=2.04$, range $=0-12)$ out of a total of 18 diversified local practices. Among the five groups of adaptation strategies, crop management practices, such as adjusting crop varieties and types, improving seedlings and shifting planting dates, were most commonly practised by households (81 per cent). Measures constituting key components of farmland management, such as enhancing soil fertility and pest control, were also widely used (53 per cent). Other groups of strategies included managing agricultural products, which was aimed primarily at strategic processing and marketing (e.g. crop and livestock products) (37 per cent), diversifying livelihoods that focussed on using other natural resources (e.g. fish ponds) and engaging in non-farm activities (e.g. small businesses and migration for remittance) (23 per cent), water resource management strategies, which consist of water and flood control (e.g. drainage), as well as improving access to water for agriculture (e.g. pumps) (20 per cent).

The main groups of adaptation practices adopted by households varied across the three study sites. Households in Takaen and Sangke Satob were more similar in terms of adaptation patterns, except for the frequency of practicing water management. The application of water management was more prevailing in Takaen than in Sangke Satob. While crop management remained the most prevalent group of measures adopted by households in Tum Ring, like in the other two provinces, product management was another key adaptation category, which was ranked second in terms of frequency.

\subsection{Results from the logit-Poisson hurdle model}

Before going into the discussion of determinants of adaptation, we tested the specifications of the logit-Poisson hurdle model against its alternatives to justify its use. First, the Poisson model was compared to the negative binomial regressions model (Long and Freese, 2001). We found no over-dispersion of the data based on the insignificant

\begin{tabular}{|c|c|c|c|c|c|}
\hline \multirow{7}{*}{$\begin{array}{l}\text { Table II. } \\
\text { Adaptation } \\
\text { strategies adopted by } \\
\text { households in the } \\
\text { study area }\end{array}$} & Adaptation measures & $\begin{array}{l}\text { Takaen } \\
(n=200)\end{array}$ & $\begin{array}{l}\text { Sangke satob } \\
\quad(n=201)\end{array}$ & $\begin{array}{l}\text { Tum ring } \\
(n=185)\end{array}$ & $\begin{array}{c}\text { Total } \\
(n=586)\end{array}$ \\
\hline & Crop management & $173(87)$ & $167(83)$ & $135(73)$ & $475(81)$ \\
\hline & Water management & $20(10)$ & $54(27)$ & $43(23)$ & $117(20)$ \\
\hline & Farm products management & $62(31)$ & $73(36)$ & $81(44)$ & $216(37)$ \\
\hline & Livelihood diversification & $55(28)$ & $40(20)$ & $38(21)$ & $133(23)$ \\
\hline & Farmland management & $137(68)$ & $118(59)$ & $56(30)$ & $311(53)$ \\
\hline & \multicolumn{5}{|c|}{ Note: Percentage of households adopting a specific type of adaptation presented in parenthesis } \\
\hline
\end{tabular}


coefficient estimated, which reflected unobserved heterogeneity among observations. This suggests that the Poisson model was in favour. We proceeded to test the two-stage decision model against the single Poisson regression. To do so, we used a likelihood- ratio (LR) test (Greene, 2008), considering that the Poisson model is nested in the double hurdle model given its generalized specification. The result was highly significant $\left(L R \chi^{2}(17)=\right.$ 43.83, $p=0.0004)$, thereby rejecting the null hypothesis that the Poisson model was appropriate.

Table III presents the results from the double hurdle model exploring the factors that influence the two-stage household adaptation decisions: whether to adopt any adaptation measures and, if so, how many. Perceived climate change (i.e. drought and flood) and improved access to water for farmland have positive and significant effects on both adaptation decision stages. At the first decision stage, the positive effect of age and a negative effect of age squared show that the probability of adaptation increases with age of household heads; however, when household heads reach a certain age, the effect of age lessens. Other factors that influence the first stage of decision-making include health status and access to market and services. The results show that the poor health of family members may constrain households to adapt; this was expected as participation in different kinds of adaptation is most likely to be labour intensive. Proximity to a main road with better access to market and other services facilitates household adaptation. Regarding the intensity of adaptation, households with more farmland are more likely to adopt a larger number of adaptation measures. We also found that physical asset accumulation and better access to credit have a positive effect on household adaptation intensity. Households with higher crop sensitivity (loss of productivity) because of drought undertake more adaptation measures.

\begin{tabular}{lcccr}
\hline & \multicolumn{2}{c}{$\begin{array}{c}\text { Decision to adapt } \\
\text { Coefficients }\end{array}$} & $p$-value & \multicolumn{2}{c}{ Intensity to adapt } \\
Variable & -0.838 & 0.334 & 0.076 & 0.179 \\
\hline Sangke Satob (1/0) & $-2.321^{* * *}$ & 0.007 & $0.202^{* * *}$ & 0.018 \\
Tum Ring (1/0) & -0.473 & 0.332 & -0.103 & 0.165 \\
Female headed HH (1/0) & $0.267^{* *}$ & 0.033 & -0.007 & 0.622 \\
Age of HH head (year) & $-0.002^{*}$ & 0.056 & 0.000 & 0.578 \\
Age (of HH head) & 0.148 & 0.261 & 0.004 & 0.817 \\
HH size (persons) & 0.095 & 0.251 & 0.000 & 0.987 \\
Education of HH head (year) & $-0.209^{*}$ & 0.067 & -0.022 & 0.496 \\
No. of sick persons (persons) & 0.255 & 0.693 & $0.052^{* * * *}$ & 0.002 \\
Farmland area (ha) & $0.844^{* *}$ & 0.001 & $0.230^{* * * *}$ & 0.000 \\
Farmland access to water & $-0.460^{*}$ & 0.051 & 0.037 & 0.265 \\
Distance to main road (km) & -0.008 & 0.582 & $0.006^{* * * *}$ & 0.008 \\
Physical assets (million Riel) & -0.418 & 0.355 & 0.040 & 0.480 \\
Trust among community & -0.473 & 0.193 & $0.092^{* * *}$ & 0.025 \\
Access to credit & $1.263^{* *}$ & 0.037 & $0.503^{* *}$ & 0.021 \\
Perception of climate change & 1.868 & 0.252 & $0.364^{* * * *}$ & 0.000 \\
Past experience with drought & -3.819 & 0.148 & -0.224 & 0.615 \\
Constant & 586 & & & \\
Number of observations & 83.41 & & & \\
Wald $\chi^{2}$ (16) & $0.0000^{* * * *}$ & & & \\
p-value & $-1,121.8267$ & & & \\
Log pseudo-likelihood & & & &
\end{tabular}

Notes: HH means household; ***; **; * Significant at 1, 5 and $10 \%$ level, respectively
Household adaptation decisions 
IJCCSM

12,1

\subsection{Results from the multivariate probit model model}

The validation of adopting the MVP model - assessing all equations simultaneously instead of the independent assessment of individual equations - was suggested in the significant result of the LR test $\left(\chi^{2}(10)=45.05, p=0.0000\right)$. The estimated correlation coefficients $(\rho \mathrm{kj})$ among various groups of adaptations were highly significant for 7 out of 10 combinations. The positive signs implied that the adoptions of these multifaceted adaptation strategies are complementary, indicating households often chose more than one adaptation strategy.

Table IV shows the results from the MVP model examining the determinants of households' choices of adaptation strategies, and we found that adoptions of different adaptation strategies are not significantly influenced by the same set of variables. Similar to the two-stage decision-making, better access to water for farmland often provides an incentive to households to adopt crop management, farm product management and farmland management adaptation strategies. The higher extent of crop productivity loss due to drought seems to have a significant positive effect on adopting strategies such as farm product management, water management and farmland management. Farmland size is positively associated with the adoption of crop management and farm product management strategies, while physical asset accumulation seems to facilitate farm products and water management strategies.

While there are factors supportive of several types of adaptations, other factors were found to facilitate only one specific type of adaptation. Human capital and household characteristics seem to only affect the choice of livelihood diversification strategy. Senior male-headed households with a higher education are more likely to diversify or shift to other livelihood alternatives (e.g. running a small business, a migrant worker for remittance), while bad health of family members becomes a barrier to this type of adaptation strategy. Interestingly, households adopting the livelihood diversification strategy often own fewer physical assets, probably because less physical capital is required and they liquidate these assets to invest in non-farm activities. Notably, perception of climate change seems to only influence adaptation of crop management. Trust among people in the community shows a positive and significant effect on undertaking crop management strategies, which underlines the fact that communication and information sharing networks may facilitate the most practiced crop management measures.

\section{Discussion}

The analyses provide some insights into households' adaptation strategies and their determinants in rural Cambodia. The findings suggest a high level of adaptation involvement among local households with three adaptation measures undertaken on average. This may be explained by the way in which adaptations were addressed and elicited. Indeed, rural households always have to adapt under various situations and risks, and often undertake measures as part of traditional farming practices without regarding them as "adaptation" (Nyong et al., 2007). Given the context of rural livelihoods faced with multiple drivers of change including climate change, adaptation measures adopted by the households in the study area are not necessarily limited to those solely initiated in response to climate change risks, unlike other research (Deressa et al., 2011). In fact, households' adaptation are often conducted to fulfil multiple objectives as an essential part of the overall risk management, which holds particularly true for rural households, who are constantly confronted with diversified stressors (O'Brien and Leichenko, 2000). For instance, some of the adaptation measures reported in our study are mainly climate-related, such as flood water control; while others, such 


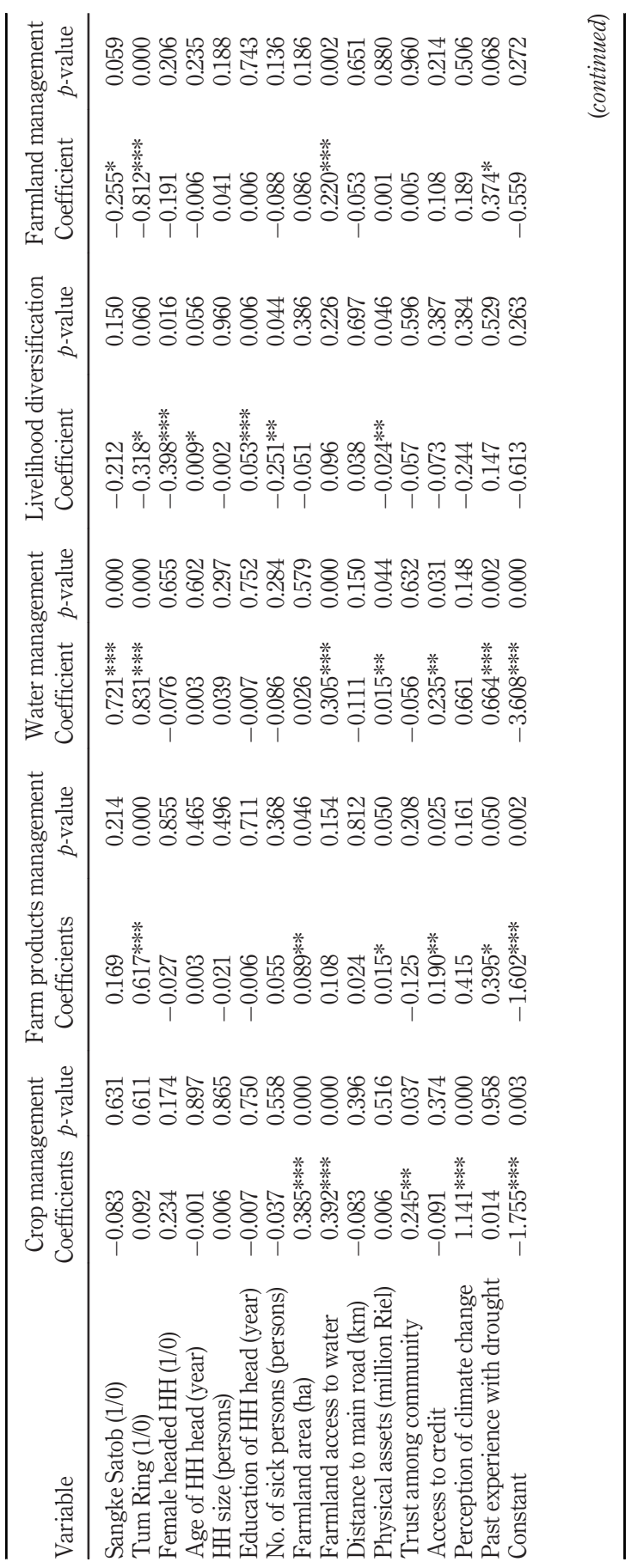

Household adaptation decisions 
IJCCSM

12,1

52

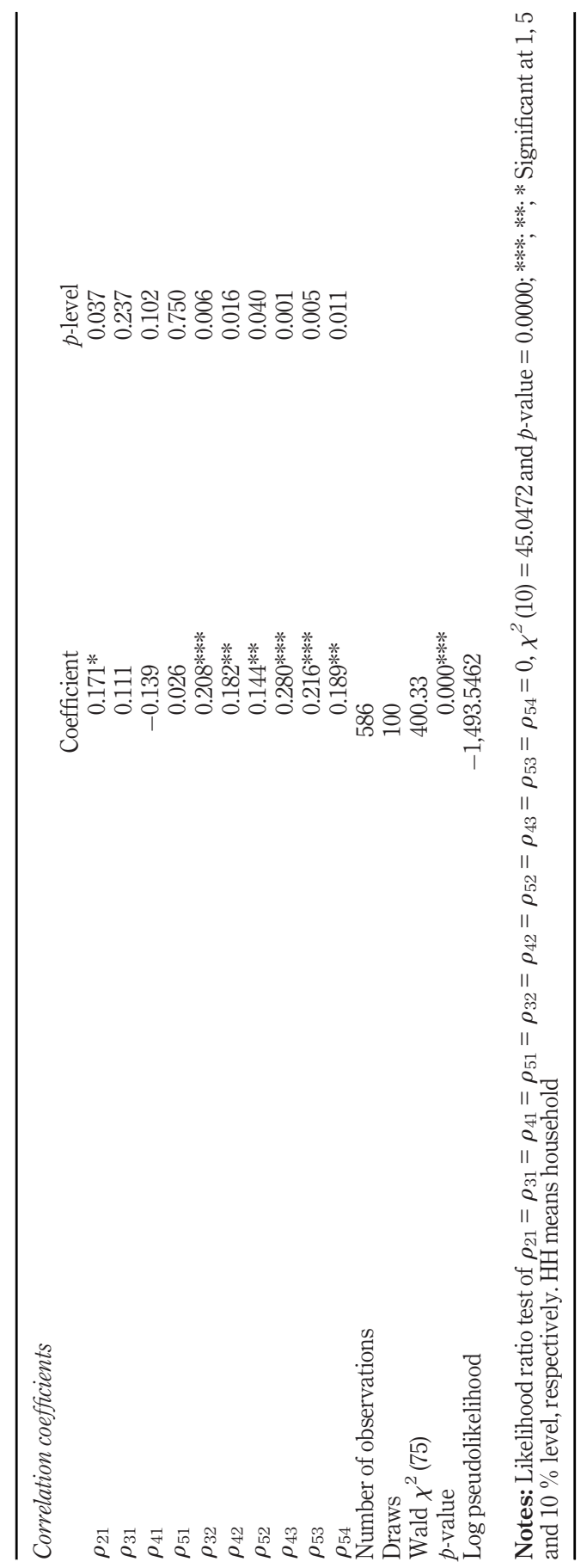

Table IV.

종 
as changing crop variety and type, are generally beneficial in terms of increasing productivity and profitability, in the meantime reducing risks from different sources (i.e. climate and market).

In this study, we have demonstrated that perceived climate change drives households' adaptation behaviour. An awareness of climate change is regarded as an important factor or even a prerequisite for adaptation, which is highlighted by quite a few theoretical and empirical studies (Deressa et al., 2011; Maddison, 2007). The results from our study; particularly the positive association found between perceived climate change and adaptation decisions provide further evidence that households, which are aware of climate change adapt more readily in a variety of ways. Thus, enhancing awareness of climate change and adaptation among households through capacity building and information dissemination can be an effective approach to promote adaptation. Our study also found that past experience with climatic risks plays a significant role in motivating adaptation; households, which bore heavier crop losses during previous droughts are more likely to adapt with greater intensity and use strategies aimed at protecting (e.g. water and farmland management) or expanding crop production. This finds support in other studies (Koerth et al., 2013; Weinstein, 1989), where personal experience with past damages was found to be a key predictor of self-protective actions against natural hazards. In the study areas where households have poor access to climate information and weak adaptation capacity, knowledge-based information and early warning mechanisms are important for effective community-based and household-level adaptation. Herein, some potential incentive packages are necessary with the support of the private sector (such as the public-private partnership with telecommunication firms) to use mobile technology for weather forecasts, early flood and drought warnings (similar to market information network for farmers via mobile phones or fund transfers via mobile network).

According to our finding, farmland size does not seem to be significantly associated with the decision to adapt, but households with large size of farmland tend to undertake more adaptation measures, especially those related to crop management practices and agricultural product processing and marketing. An associated issue is that insecure land tenure may become a barrier to farmers allocating land or making investments in certain adaptation measures, such as water management infrastructure, as pointed out by many studies (Maddison, 2007; Piya et al., 2013). Farmland access to water is found to be a critical factor in our study, which influences adaptation status and intensity decisions, as well as adaptation strategy choices regarding farmland, water and crop management. This complies with other findings about the significant impact of access to irrigation on adaptation (Bryan et al., 2013). In the studied communities, crop production is mainly rainfed agriculture and irrigation systems are not available. Appropriate water management facilities and technologies should, therefore, be promoted and enhanced to facilitate the adoption of agriculture-related adaptation options in the study area.

Households located closer to the main road and with better access to market and services are found most likely to adapt in our study, which is largely in line with other studies (Below et al., 2012; Deressa et al., 2011; Maddison, 2007). However, proximity to the main road is not significantly associated with adaptation intensity or any adaptation strategy choices. Possible reasons for this could be weak infrastructure and a lack of facilities in general in the study areas. This indicates that poor access to inputs, technologies and information, together with high transaction and opportunity costs, constitute critical entry barriers to further participation in adaptation (Hassan and Nhemachena, 2008; Piya et al., 2013). Our findings also suggest that household physical assets serve as a significant contributor to adaptation intensity and promote the adoption of water and agricultural product
Household adaptation decisions 
IJCCSM 12,1

management strategies, while its impact is negatively significant on the adoption of livelihood diversification strategy (e.g. small business, migratory work for remittance). Possible explanations may lie in that diversification has a lower demand for these assets or that these assets could actually be transformed into financial capital for investment in other non-farm activities.

There exists ample empirical evidence for credit availability as an influential factor in facilitating local adaptation (Below et al., 2012; Bryan et al., 2013; Deressa et al., 2011; Hassan and Nhemachena, 2008; Piya et al., 2013; Tambo and Abdoulaye, 2012), and it is further substantiated through our study that better credit accessibility enables households to undertake more adaptation measures, especially in water management and farm product management strategies in the local communities. To facilitate adaptation, investments and support could be directed to microcredit schemes, a social fund for community-based adaptation and weather-based insurance.

Our study suggests that male-headed, well-educated households and household members who are in good health are more likely to adapt by means of livelihood diversification. The result echoes the findings of other studies (Bryan et al., 2013), where men - because of their stronger financial situation and better access to information/resource use - tended to adopt certain adaptation strategies (e.g. change animal feed). The result also confirms the positive effect of education on varied adaptation behaviours disclosed by others (Deressa et al., 2009; Tambo and Abdoulaye, 2012). The analyses indicate that continuous investment in education and medical care systems, as well as measures that empower women should be emphasized as a key policy option in the study area to strengthen households' adaptive capacity. Furthermore, we found that trust among households is one of the key motivators for implementing crop management strategies in the study area. This may be because of that trust serves as the basis for social networking and information sharing about farming practices and crops among community members. Our study coincides with other studies, which highlight the essential role of social capital in the uptake of adaptation (Comoé and Siegrist, 2013; Esham and Garforth, 2012). Consequently, policies, which aim to reinforce community institutions and bonds are considered an effective means to facilitate adaptation to climate risks.

The significant coefficients of location dummies indicate that households living in different geographical settings used local-specific adaptation approaches, which was also found in other studies (Bryan et al., 2013; Deressa et al., 2009; Piya et al., 2013). This implies that no one-size-fits-all adaptation strategy could be used across all communities. The formulation of adaptation strategies needs to be tailored to the local context and accommodate the specific needs and constraints of targeted communities (Bryan et al., 2009). It is important to understand the fundamental process and drivers regarding adaptation at the community and household levels.

The three-stage analytical approach applied in our study provides a potential way to systematically assess household adaptation decision-making in other rural settings. However, site-specific selection of variables is needed to allow for the incorporation of local and contextual considerations. The method of using the unweighted sum of adaptation measures may not be a good reflection of the relative importance and contribution of different options towards enhanced adaptive capacity. This could be further refined in future research using objective weighting schemes derived from e.g. principal component analysis (Li et al., 2016). Moreover, this study did not investigate the effectiveness or the associated costs and benefits of particular adaptation options, which points to future research in this area. 


\section{Conclusion}

This study took a systematic approach to exploring the determinants of household adaptation decision-making from three dimensions, namely, adaptation status, adaptation intensity and choices of adaptation strategy. Key capital assets that determine household adaptation behaviours, which were identified through the double hurdle model and MVP model analyses, correspond well with the hypothesized results and existing empirical studies, and contribute to the literature with new angles and in-depth results at various adaptation decision-making stages. This paper provides an analysis of households' own autonomous adaptation measures practiced at present, although the speed and magnitude of climate-induced changes may seriously challenge their adaptive capacity in the future. Considering the significant influence of households' climate change perceptions on adaptation, actions should be taken to promote channels of climate information dissemination and sharing (e.g. through dialogues) at the village and sub-district levels. In this study, potential interventions derived from influential factors for adaptation decisions include improvement of rural infrastructure and services (i.e. education, healthcare, market facilities), the strengthening of local institutions and social capital, development and promotion of water management facilities and technologies, as well as micro-credit and insurance mechanisms. More importantly, adaptation strategies and actions should be tailored to the local context and mainstreamed into existing community development policy and planning process, involving multi-stakeholders.

\section{References}

Adger, W.N. (2003), "Social capital, collective action, and adaptation to climate change", Economic Geography, Vol. 79 No. 4, pp. 387-404.

Angelsen, A., Larsen, H.O., Lund, J.F., Smith-Hall, C. and Wunder, S. (Eds) (2011), Measuring Livelihoods and Environmental Dependence: Methods for Research and Fieldwork, Earthscan, London.

Below, T.B., Mutabazi, K.D., Kirschke, D., Franke, C., Sieber, S., Siebert, R. and Tscherning, K. (2012), "Can farmers' adaptation to climate change be explained by socio-economic household-level variables?”, Global Environmental Change, Vol. 22 No. 1, pp. 223-235.

Bryan, E., Deressa, T.T., Gbetibouo, G.A. and Ringler, C. (2009), "Adaptation to climate change in Ethiopia and South Africa: options and constraints", Environmental Science and Policy, Vol. 12 No. 4, pp. 413-426.

Bryan, E., Ringler, C., Okoba, B., Roncoli, C., Silvestri, S. and Herrero, M. (2013), “Adapting agriculture to climate change in Kenya: household strategies and determinants", Journal of Environmental Management, Vol. 114, pp. 26-35.

Bylander, M. (2015), "Depending on the sky: environmental distress, migration, and coping in rural Cambodia", International Migration, Vol. 53 No. 5, pp. 135-147.

Cappellari, L. and Jenkins, S.P. (2003), "Multivariate probit regression using simulated maximum likelihood", The Stata Journal: Promoting Communications on Statistics and Stata, Vol. 3 No. 3, pp. 278-294.

Comoé, H. and Siegrist, M. (2013), "Relevant drivers of farmers' decision behavior regarding their adaptation to climate change: a case study of two regions in côte d'Ivoire", Mitigation and Adaptation Strategies for Global Change, Vol. 1, pp. 1-21, doi: 10.1007/s11027-013-9486-7.

Cragg, J.G. (1971), "Some statistical models for limited dependent variables with application to the demand for durable goods", Econometrica, Vol. 39 No. 5, pp. 829-844.

D’Agostino, A.L. and Sovacool, B.K. (2011), "Sewing climate-resilient seeds: implementing climate change adaptation best practices in rural Cambodia", Mitigation and Adaptation Strategies for Global Change, Vol. 16, pp. 699-720. 
IJCCSM 12,1

Deressa, T.T., Hassan, R.M. and Ringler, C. (2011), "Perception of and adaptation to climate change by farmers in the Nile basin of Ethiopia", The Journal of Agricultural Science, Vol. 149 No. 1, pp. 23-31.

Deressa, T.T., Hassan, R.M., Ringler, C., Alemu, T. and Yesuf, M. (2009), "Determinants of farmers' choice of adaptation methods to climate change in the Nile Basin of Ethiopia", Global Environmental Change, Vol. 19 No. 2, pp. 248-255.

Esham, M. and Garforth, C. (2012), "Agricultural adaptation to climate change: insights from a farming community in Sri Lanka", Mitigation and Adaptation Strategies for Global Change, Vol. 18, pp. 1-15.

Evers, J. and Pathirana, A. (2018), Adaptation to Climate Change in the Mekong River Basin: introduction to the Special Issue, Springer, New York, NY.

Füssel, H.M. and Klein, R.J.T. (2006), "Climate change vulnerability assessments: an evolution of conceptual thinking”, Climatic Change, Vol. 75 No. 3, pp. 301-329.

Gbetibouo, G.A., Hassan, R.M. and Ringler, C. (2010), "Modelling farmers' adaptation strategies for climate change and variability: the case of the Limpopo Basin, South Africa”, Agrekon, Vol. 49 No. 2, pp. 217-234.

Gong, Y., Li, H., Parks, M., Pang, J. and de Fraiture, C. (2018), "The role of social capital for farmers' climate change adaptation in Lancang River basin in China”, Climatic Change, Vol. 149 No. 1, pp. $75-89$.

Greene, W. (2008), Econometrics Analysis, Prentice Hall, Englewood Cliffs.

Grothmann, T. and Patt, A. (2005), "Adaptive capacity and human cognition: the process of individual adaptation to climate change", Global Environmental Change, Vol. 15 No. 3, pp. 199-213.

Hassan, R. and Nhemachena, C. (2008), "Determinants of African farmers' strategies for adapting to climate change: multinomial choice analysis", African Journal of Agricultural and Resource Economics, Vol. 2, pp. 83-104.

IPCC (2007), "Climate change: impacts, adaptation, and vulnerability”, in Parry, M.L., Canziani, O.F., Palutikof, J.P. (Eds), Contribution of Working Group II to the Fourth Assessment Report of the Intergovernmental Panel on Climate Change, Cambridge University Press, Cambridge, pp. 1-131.

Jones, A. (1989), “A double-hurdle model of cigarette consumption”, Journal of Applied Econometrics, Vol. 4 No. 1, pp. 23-29.

Kim, J., Park, H., Chun, J. and Li, S. (2018), “Adaptation strategies under climate change for sustainable agricultural productivity in Cambodia", Sustainability, Vol. 10 No. 12, pp. 45-37.

Koerth, J., Vafeidis, A.T., Hinkel, J. and Sterr, H. (2013), "What motivates coastal households to adapt pro-actively to sea-level rise and increasing flood risk?", Regional Environmental Change, Vol. 1, pp. 1-13.

Langyintuo, A.S. and Mungoma, C. (2008), "The effect of household wealth on the adoption of improved maize varieties in Zambia", Food Policy, Vol. 33 No. 6, pp. 550-559.

Li, Q.R., Amjath-Babu, T.S. and Zander, P. (2016), "Role of capitals and capabilities in ensuring economic resilience of land conservation efforts: a case study of the grain for green project in china's loess hills", Ecological Indicators, Vol. 71, pp. 634-644.

Long, J. and Freese, J. (2001), Regression Models for Categorical Dependent Variables Using Stata, Stata Press, TX.

Ly, P., Jensen, L.S., Bruun, T.B., Rutz, D. and de Neergaard, A. (2012), "The system of rice intensification: adapted practices, reported outcomes and their relevance in Cambodia", Agricultural Systems, Vol. 113, pp. 16-27.

Maddison, D.J. (2007), “The perception of and adaptation to climate change in Africa”, Policy Research Working Paper 4308, The World Bank. 
Mertz, O., Halsnæs, K., Olesen, J.E. and Rasmussen, K. (2009), "Adaptation to climate change in developing countries”, Environmental Management, Vol. 43 No. 5, pp. 743-752.

Molua, E.L. (2009), "Accommodation of climate change in coastal areas of Cameroon: selection of household-level protection options", Mitigation and Adaptation Strategies for Global Change, Vol. 14 No. 8, pp.721-735.

Mullahy, J. (1986), "Specification and testing of some modified count data models", Journal of Econometrics, Vol. 33 No. 3, pp. 341-365.

NCDD (2010), "National committee for sub-national democratic development", available at: http://db. ncdd.gov.kh/cdbonline/home/index.castle

Nguyen, H., Prabhakar, S. and Shaw, R. (2009), "Adaptive drought risk reduction in Cambodia: reality, perceptions and strategies", Environmental Hazards, Vol. 8 No. 4, pp. 245-262.

Noltze, M., Schwarze, S. and Qaim, M. (2012), "Understanding the adoption of system technologies in smallholder agriculture: the system of rice intensification (SRI) in Timor leste", Agricultural Systems, Vol. 108, pp. 64-73.

Nyong, A., Adesina, F. and Elasha, B.O. (2007), "The value of indigenous knowledge in climate change mitigation and adaptation strategies in the African Sahel", Mitigation and Adaptation Strategies for Global Change, Vol. 12 No. 5, pp. 787-797.

O’Brien, K.L. and Leichenko, R.M. (2000), "Double exposure: assessing the impacts of climate change within the context of economic globalization”, Global Environmental Change, Vol. 10, pp. 221-232.

PEN (2007), "PEN technical guidelines version 4. Poverty environment network", available at: www. cifor.org/pen/research-tools/the-pen-technical-guidelines.html (accessed 11 November 2013).

Piya, L. (2019), Socio-Economic Issues of Climate Change: A Livelihood Analysis from Nepal, Springer, Singapore.

Piya, L., Maharjan, K.L. and Joshi, N.P. (2013), "Determinants of adaptation practices to climate change by Chepang households in the rural mid-hills of Nepal", Regional Environmental Change, Vol. 13 No. 2, pp. 437-447.

Ra, K., Pichdara, L., Dararath, Y., Jiao, X. and Smith-Hall, C. (2011), Towards Understanding HouseholdLevel Forest Reliance in Cambodia - Study Sites, Methods, and Preliminary Findings Vol 60, University of Copenhagen, Copenhagen.

Resurreccion, B.P., Sajor, E.E. and Fajber, E. (2008), Climate Adaptation in Asia: Knowledge Gaps and Research Issues in Southeast Asia, Institute for Social and Environmental Transition-Nepal (ISET-Nepal), Lalitpur.

Scoones, I. (1998), Sustainable Rural Livelihoods: A Framework for Analysis, Institute of Development Studies, Brighton.

Smit, B. and Wandel, J. (2006), “Adaptation, adaptive capacity and vulnerability”, Global Environmental Change, Vol. 16 No. 3, pp. 282-292.

Smit, B., Burton, I., Klein, R.J. and Wandel, J. (2000), “An anatomy of adaptation to climate change and variability", Climatic Change, Vol. 45, pp. 223-251.

Sovacool, B.K., D’Agostino, A.L., Rawlani, A. and Meenawat, H. (2012), "Improving climate change adaptation in least developed Asia", Environmental Science and Policy, Vol. 21, pp. 112-125.

Tabet, A. (2007), Bayesian Inference in the Multivariate Probit Model, The University of British Columbia, Vancouver.

Tambo, J.A. and Abdoulaye, T. (2012), "Climate change and agricultural technology adoption: the case of drought tolerant maize in rural Nigeria", Mitigation and Adaptation Strategies for Global Change, Vol. 17 No. 3, pp. 277-292.

Vincent, K. (2007), "Uncertainty in adaptive capacity and the importance of scale", Global Environmental Change, Vol. 17 No. 1, pp. 12-24. 
IJCCSM

12,1

58
Waibel, H., Pahlisch, T.H. and Völker, M. (2018), "Farmers' perceptions of and adaptations to climate change in Southeast Asia: the case study from Thailand and Vietnam", Climate Smart Agriculture, Springer, Cham, pp. 137-160.

Wang, J.X., Mendelsohn, R., Dinar, A. and Huang, J.K. (2010), "How Chinese farmers change crop choice to adapt to climate change", Climate Change Economics, Vol. 01 No. 3, pp. 167-185.

Weinstein, N.D. (1989), "Effects of personal experience on self-protective behavior", Psychological Bulletin, Vol.105, p. 31.

Wolf, J., Adger, W.N., Lorenzoni, I., Abrahamson, V. and Raine, R. (2010), "Social capital, individual responses to heat waves and climate change adaptation: an empirical study of two UK cities", Global Environmental Change, Vol. 20 No. 1, pp. 44-52.

Yohe, G. and Tol, R.S.J. (2002), "Indicators for social and economic coping capacity - moving toward a working definition of adaptive capacity", Global Environmental Change, Vol. 12 No. 1, pp. 25-40.

\section{Further reading}

Füssel, H.M. (2007), "Adaptation planning for climate change: concepts, assessment approaches, and key lessons”, Sustainability Science, Vol. 2 No. 2, pp. 265-275.

\section{Corresponding author}

Zhen Liu can be connected at: zhenliu_cn@yahoo.com

For instructions on how to order reprints of this article, please visit our website: www.emeraldgrouppublishing.com/licensing/reprints.htm

Or contact us for further details: permissions@emeraldinsight.com 